\title{
Experimental Study on Random Vibration Fatigue S-N Curve of GH188 Alloy Under High Temperature Environment
}

\author{
Chao Qu ${ }^{\text {a, }}$, Hongwei Zhou, Xuefeng Zou
}

\author{
Aircraft Strength Research Institute of China, Xi,an 710065, China \\ a quchao50@163.com
}

Keywords: High-temperature random vibration fatigue; S-N curve; GH188 superalloy

\begin{abstract}
A random vibration fatigue test system developed by the company was used to conduct a random vibration fatigue test at a temperature of $25^{\circ} \mathrm{C} / 450^{\circ} \mathrm{C}$ for a typical plate element of GH188 alloy, and the random vibration fatigue median life of S-N curve of GH188 superalloy at a temperature of $25^{\circ} \mathrm{C} / 450^{\circ} \mathrm{C}$ was obtained. The experimental results show that under the condition of $450^{\circ} \mathrm{C}$ the $\mathrm{S}-\mathrm{N}$ value of the random vibration median life of the GH188 deformed superalloy is lower than that of the room temperature, indicating that the fatigue life of the GH188 deformed alloy is shortened with the increase of temperature.
\end{abstract}

\section{Introduction}

GH188 is a solid-solution-strengthened cobalt-based superalloy, which has good mechanical property and corrosion resistance at high temperature. It is mainly applied to high temperature components of aero-engines and missiles, such as combustor, afterburner and exhaust nozzle[1]. In the turbojet, turbofan and ramjet, the compression of air and the combustion process in the combustion chamber make the temperature of the hot-end components higher, especially in the combustion chamber. High temperature will change the properties and fatigue life of structural materials, that is to change the S-N curve of structural materials. GH188 alloy parts need to work in harsh high-temperature environment for a long time, and bear vibration noise and load at the same time. Therefore, it is necessary to study the fatigue properties of GH188 alloy materials under high temperature by means of experimental methods.

In engineering, the nominal stress method is used to evaluate the service life of structures. The S$\mathrm{N}$ curve of vibration fatigue performance of components is adopted, and the ability of structure to bear alternating load is evaluated by linear damage superposition approach. For the acoustic-vibration fatigue properties of materials/typical structures, a lot of research work has been carried out at home and abroad[2]. Before the 1980s, the constant amplitude fatigue S-N curve (normal temperature and high temperature) was widely used, then the study of equivalent damage relations of constant amplitude and random vibration fatigue was carried out, a lot of constant amplitude vibration fatigue $\mathrm{S}-\mathrm{N}$ curves were converted into equivalent random vibration fatigue $\mathrm{S}-\mathrm{N}$ curves. For the acoustic fatigue problem of structures, directly tested data of random amplitude fatigue S-N curve were commonly used[3].

In this paper, a set of high-temperature random vibration fatigue test system is used to conduct random vibration fatigue tests under the conditions of $25^{\circ} \mathrm{C} / 450^{\circ} \mathrm{C}$, for typical plate elements of GH188 superalloy, and the random vibration fatigue S-N curves of GH188 superalloy were obtained at two temperatures.

\section{A Brief Introduction to Random Vibration Fatigue Test}

\subsection{Specimen and Testing System}

There are 52 specimens of GH188 deformed high temperature alloy plates in the shape of a dog bone, among which 40 pieces are used for the test at $450^{\circ} \mathrm{C}$, and 12 for the test at $25^{\circ} \mathrm{C}$, The sizes are 
shown in Figure 1. The parameters of GH188 are shown in Table 1. A medium temperature strain gauge is attached to the center of each specimen, and the k-type thermocouple is welded to the position of the strain gauge.

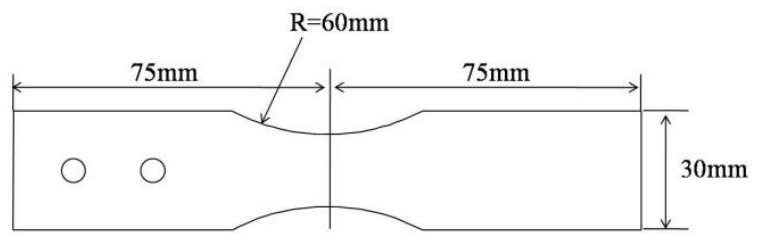

Fig.1 Schematic diagram of the specimen

Table 1. Physical parameters of GH188 at 25, and 450,

\begin{tabular}{ccc}
\hline Temperature $/ \mathrm{T}\left({ }^{\circ} \mathrm{C}\right)$ & 25 & 450 \\
\hline Modulus of elasticity $/ \mathrm{E}(\mathrm{GPa})$ & 213 & 170 \\
Poisson's ratio $/ \mu$ & 0.301 & 0.320 \\
Linear expansion coefficient $/ \alpha\left(10^{-6 \circ} \mathrm{C}^{-1}\right)$ & 13.4 & 13.7 \\
Density $/ \sigma\left(10^{3} \mathrm{~kg} / \mathrm{m}^{3}\right)$ & 9.09 & 9.09 \\
Thermal conductivity $/ \mathrm{K}\left(\mathrm{W} / \mathrm{m}^{\circ} \mathrm{C}\right)$ & 15.4 & 20.1 \\
\hline
\end{tabular}

The test fixture is installed on the vibration slide platform. The specimens are installed on the fixture and each set of specimens 8 is installed each time. The test parts are installed side by side in the fixture, and the direction of vibration loading is perpendicular to the surface of the specimen. Both sides of the test parts are heated at the same distance on both sides of the test parts at the same distance, as shown in Figure 2.

\subsection{Test Load and Control}

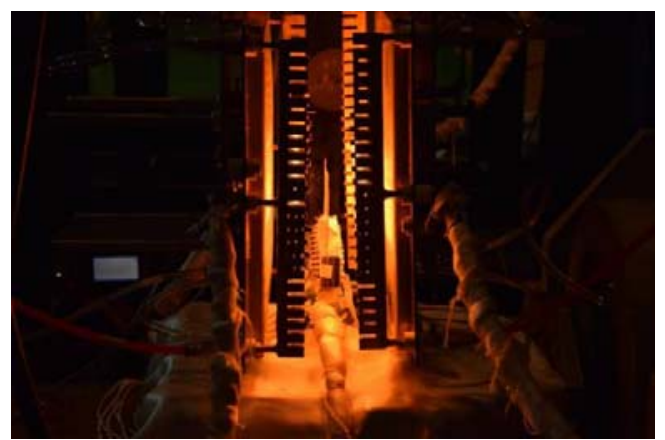

Fig.2 Photo of the test system

There were 7 groups of random vibration fatigue tests, of which 5 groups of high temperature tests $\left(450^{\circ} \mathrm{C}\right)$ and 2 groups of normal temperature tests $\left(25^{\circ} \mathrm{C}\right)$. The vibration load spectrum is a plane random vibration excitation with a frequency range of $70 \mathrm{~Hz}-95 \mathrm{~Hz}$. The test load of each group is shown in Table 2.

Table 2. The schedule of random vibration fatigue test

\begin{tabular}{cccc}
\hline Grouping & Temperature (centigrade) & Load magnitude & Number \\
\hline A group & 450 & $3.2 \mathrm{~g}$ & 8 \\
B group & 450 & $2.4 \mathrm{~g}$ & 8 \\
C group & 450 & $4.0 \mathrm{~g}$ & 8 \\
D group & 450 & $2.8 \mathrm{~g}$ & 8 \\
E group & 450 & $2.0 \mathrm{~g}$ & 8 \\
F group & 25 & $2.4 \mathrm{~g}$ & 6 \\
G group & 25 & $3.2 \mathrm{~g}$ & 6 \\
\hline
\end{tabular}


The temperature field of the test part is simulated by the transient thermal environment simulation system in the test. The system is composed of a quartz lamp radiation heater, a temperature sensor, a temperature controller and a silicon controlled silicon control system. The basic principle of transient thermal environment simulation system is carried out by heating quartz lamp radiation, the temperature measurement temperature sensor control point and compared with the experimental values obtained according to control deviation, temperature deviation from the heating control device driver SCR correction input to the instantaneous power of the heater, to form a closed loop test the temperature control system to achieve precise temperature control. In the test, the average temperature of all the test parts of each group was measured as the measured temperature. Figure 3 is the curve between the set temperature and the measured temperature of the test temperature rise section. Table 3 gives a comparison between the set temperature and the measured temperature at $450^{\circ} \mathrm{C}$ degrees centigrade at high temperature random vibration fatigue test.

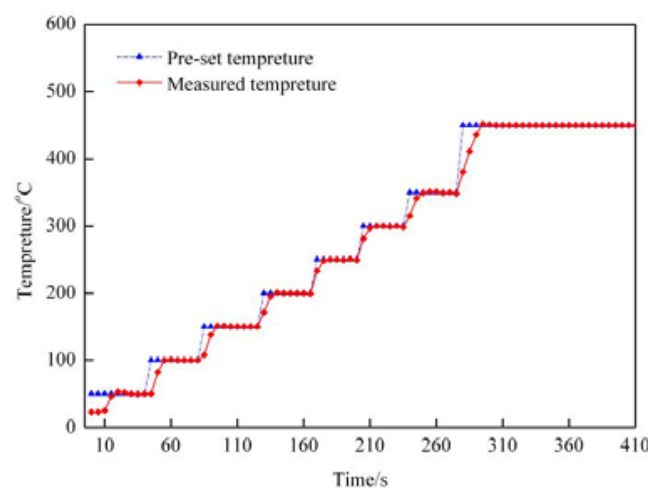

Fig. 3 Comparison of pre-set temperature and measured temperatur at the period of increase of temperature

Table 3. Comparison of pre-set temperature and measured temperatur at $450^{\circ} \mathrm{C}$

\begin{tabular}{cccc}
\hline Time (s) & $\begin{array}{c}\text { Preset temperature } \\
\text { (centigrade) }\end{array}$ & $\begin{array}{c}\text { Measured temperature } \\
, \%\end{array}$ & error (\%) \\
\hline 3000 & 450 & 451.2 & $0.27 \%$ \\
4000 & 450 & 451.3 & $0.29 \%$ \\
5000 & 450 & 449.3 & $-0.16 \%$ \\
6000 & 450 & 449.2 & $-0.18 \%$ \\
7000 & 450 & 451.7 & $0.38 \%$ \\
8000 & 450 & 449.8 & $-0.04 \%$ \\
\hline
\end{tabular}

From Figure 3, we can see that during test temperature loading, the surface temperature of specimen increases step by step, and the measured temperature change of specimen is lagged behind the set temperature, but with time passing, the measured temperature will keep approaching the set temperature. It can be seen from table 3 that when the temperature of the specimen reaches 450 degrees, the measured temperature is highly consistent with the set temperature during the fatigue test. The temperature control error is less than $1 \%$, which indicates that the temperature control is accurate and effective in the process of high temperature fatigue test.

\section{Test Results and Results Analysis}

\subsection{Test Results}

When the peak frequency of strain response of the specimen is reduced by more than $5 \%$, the current time is recorded as the failure time of the specimen, and the total time of the test failure is the life time of each specimen. The total cycle times of each specimen can be obtained by multiplying the peak frequency of the strain response of each specimen. 
The mid value fatigue life S-N curve of the GH188 deformation superalloy material obtained by the least square method at $25^{\circ} \mathrm{C}$, and $450^{\circ} \mathrm{C}$, is shown in Figure 4 . Under the condition of $25^{\circ} \mathrm{C}$, , the curve equation is as follows:

$$
\lg S=-0.196 \lg N+3.788
$$

Under the condition of $450^{\circ} \mathrm{C}$, the curve equation is as follows:

$$
\lg S=-0.263 \lg N+4.019
$$

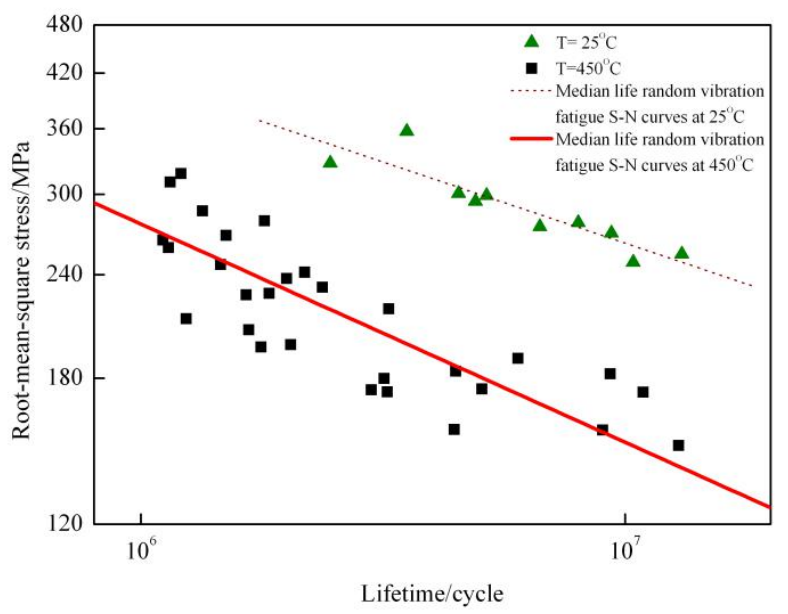

Fig.4 Comparison of median life random vibration fatigue S-N curves between $25^{\circ} \mathrm{C}$ and $450^{\circ} \mathrm{C}$

\subsection{Analysis of Experimental Results}

To judge whether a fitting curve is good or bad, it usually depends on its linear correlation. In order to ensure that the regression equation can reflect the correlation between random variables, the correlation coefficient should be satisfied. The minimum value of the correlation coefficient. If the regression equation can be used to describe the relationship between random variables, the correlation coefficient absolute value should not be less than the minimum values of the correlation coefficients.

For the formula (1) and formula (2), the correlation coefficients are 0.775 and 0.647 respectively. According to the literature, for the formula (1) and formula (2), if the confidence level is $95 \%$, the minimum values of the correlation coefficients are 0.532 and 0.304 , respectively. It can be seen that the regression equation can be used to describe the relationship between variables.

From Figure 4, we can see that in the high cycle fatigue range (106-107), under the same stress level, the fatigue life of GH188 deformation superalloy material at $25^{\circ} \mathrm{C}$, is significantly longer than that of $450^{\circ} \mathrm{C}$

\section{Conclusion}

Through the test, we can get the following conclusions:

1) The mid value fatigue life $\mathrm{S}-\mathrm{N}$ curve of the GH188 deformation superalloy material at $25^{\circ} \mathrm{C}$ and $450^{\circ} \mathrm{C}$ can be express like: $\operatorname{lgS}=0.196 \lg \mathrm{N}+3.788450$ and $\operatorname{lgS}=0.263 \lg \mathrm{N}+4.019$ respectively;

2) In the high cycle fatigue range (106-107) and the same stress level, the random vibration fatigue life of GH188 deformed superalloy material at $25^{\circ} \mathrm{C}$ is significantly longer than that of $450^{\circ} \mathrm{C}$.

\section{References}

[1]. LEI Hang,Hu Xuteng,Song Yingdong. Study and Application of Creep Constitutive Model of GH188 Superalloy. Mechanical Science and Technology for Aerospace Engineering[J]. 2011, 30(10): 1623-1628. (in Chinese).

[2]. QU Chao. The High Cycle Random Fatigue Test Report of the High Tempreature Superalloy GH188: 00-623S-2016-105-0063[R]. Aircraft Strength Research Institute of China Engineering Report. 2016. (in Chinese). 
[3]. CHEN Chuan Yao. Fatigue and Fracture[M]. Huazhong University of Science and Technology Press. 2002. 61-62. (in Chinese). 